\title{
DEBATES: SOBRE EL ROL DE \\ LA ESCUELA Y DE LOS EDUCADORES \\ DE ADULTOS EN LAS CÁRCELES
}

\author{
Francisco José Scarfó ${ }^{1}$ \\ Maria Eugenia Cuellar ${ }^{l}$ \\ Deborah Sabrina Mendoza ${ }^{1}$
}

RESUMEN: Cuando se realiza una caracterización mínima del ejercicio del rol docente en la educación pública en las cárceles, importa basarse en el rol profesional pedagógico emergente $y$ en particular sobre la adaptabilidad y/o contextualidad de la educación en tanto derecho humano que constituye la clave para pensar a la formación y la selección de los/as educadores en una articulación de una serie de componentes fundamentales, destacando dos de éstos: las condiciones de su apropiación desde la perspectiva de quien aprende (en nuestro caso jóvenes o adultos privados de su libertad) y las características de las situaciones específicas en que tendrá lugar la enseñanza, en función de los contextos concretos de actuación (o sea en la cárcel).

Palabras clave: Escuela en la cárcel. Formación del profesorado. Educación como un derecho.

\section{Debates: about the role of school and adult educators in prisons}

ABSTRACT: When a minimal characterization of the teaching
role is done in prison public education, based on the emerging
pedagogical professional role and especially the adaptability
and/or contextualization of education as a human right, it is

${ }^{1}$ Grupo de Estudios sobre Educación en Cárceles (GESEC-NORTE) - Salta, Argentina. E-mail: franciscoscarfo@speedy.com.ar

DOI: $10.1590 / C C 0101-32622016162883$ 
crucial to reflect on training and selection of educators regarding a number of key components, mainly two: the conditions of appropriation from the learner's perspective (in our case a young adult deprived of his/her freedom), and the characteristics of specific situations in which teaching takes place, depending on the specific contexts of action (i.e. the prison).

Keywords: School in prison. Teacher training. Education as a right.

\section{INTRODUCCIÓN: ¿LA CÁRCEL ES UN LUGAR PARA ENSEÑAR?}

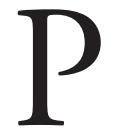

artiendo de los aportes de Michel Foucault (2003) en "Vigilar y castigar: el nacimiento de la cárcel”, la prisión es menos reciente de lo que se dice. La forma prisión preexiste a su utilización sistemática en las leyes penales. Se ha constituido en el exterior del aparato judicial, cuando se elaboraron, a través de todo el cuerpo social, los procedimientos para repartir a los individuos, fijarlos y distribuirlos espacialmente, clasificarlos, obtener de ellos el máximo de tiempo y fuerzas, educar sus cuerpos, codificar sus comportamientos continuos, mantenerlos en una viabilidad sin lagunas, formar entorno de ellos un aparato de observación, registro y notaciones, y constituir sobre ellos un saber que se acumula y se centraliza. La forma general de un equipo para volver a los individuos dóciles y útiles, por un trabajo preciso sobre su cuerpo, ha diseñado la institución-prisión, antes de que la ley la definiera como la pena por excelencia.

Foucault (2003) continúa asegurando en esta obra que la prisión marca seguramente un momento importante en la historia de la justicia penal: su acceso a la "humanidad". Además, es un momento importante para los mecanismos disciplinarios que el nuevo poder de clase estaba desarrollando: aquél en el que invadían la institución judicial. Una nueva legislación define el poder de castigar como una función general de la sociedad que se ejerce de la misma manera sobre todos sus miembros y en la que cada uno de ellos está igualmente representado; pero al hacer de la detención la pena por excelencia, esa nueva legislación introduce procedimientos de dominación característicos de un tipo particular de poder. 
La cárcel actúa como una "prisión-castigo", la cual ha aparecido tan ligada con el funcionamiento propio de la sociedad, que ha hecho olvidar todos los demás castigos que los reformadores del siglo XVIII habían imaginado. Pareció sin alternativa, y llevada por el movimiento mismo de la historia:

No ha sido la casualidad, no ha sido el capricho del legislador los que han hecho del encarcelamiento la base y el edificio casi entero de nuestra escala penal actual: es el progreso de las ideas y el suavizamiento de las costumbres (MEENEN, 1857, p. 233-234).

Desde una postura crítica, Foucault (2008, p. 234) dirá que "se saben todos los inconvenientes de la prisión, y que es peligrosa cuando no es inútil. Y, no obstante, no se "ve" por qué reemplazarla. Es la detestable solución que no se puede evitar".

En reconocimiento a los aportes de este teórico en la descripción esencial de la institución cárcel, nos preguntamos si ante tales características hay lugar y consonancia con los fines que sigue la educación. Claramente se evidencian lógicas diferentes.

La 'educación es un derecho humano fundamental', esencial para poder ejercitar todos los demás derechos y que 'tiene como fin el desarrollo integral del sujeto'. Esto re-significa tanto al sujeto como a su historia. Que una persona acceda a la educación implica entonces que pueda crear un lazo de pertenencia a la sociedad, a la transmisión y la recreación de la cultura. Es el Estado quien debe garantizar y promover el goce efectivo de éste y de todos los derechos humanos, ya que en teoría la persona encarcelada sólo está privada de su libertad ambulatoria.

La pregunta que se queda es lo que sucede en el caso que el Estado debe garantizar al mismo tiempo el cumplimiento de la pena y la garantía de este derecho inalienable. ¿Qué sucede con los sujetos que intervienen?

Entre la cárcel y el derecho a la educación, aparecen los educadores transitando. La escuela pública con una función, un rol, un trabajo específico y concreto: llevar adelante los procesos de enseñanza y aprendizaje hacia las personas presas y en el contexto de la prisión. 
Debe si cuestionar como realizar la labor docente cuando no están definidas las fronteras de la institución escolar y la institución punitiva. Las preguntas que surgen al respecto son: ¿La escuela al concentrarse dentro de la cárcel pertenece a la misma? ¿Teniendo lógicas diferentes la escuela debería encontrarse dentro de la cárcel? De no ser así, ¿¿de qué manera se garantiza el acceso a la educación?

\section{LOS DOCENTES FRENTE A LA ¿CÁRCEL-ESCUELA O ESCUELA-CÁRCEL?}

Siguiendo esta línea, una caracterización mínima del ejercicio del rol docente en la educación en cárceles, que es basado en el rol profesional pedagógico emergente, se encuentra en el texto de Dicker y Terigi (1997), según el cual la formación de los educadores debe dar cuenta de la articulación de una serie de componentes, con destaque para el presente trabajo dos de éstos: las condiciones de su apropiación desde la perspectiva de quien aprende (en este caso jóvenes o adultos privados de su libertad), y las características de las situaciones específicas en que tendrá lugar la enseñanza, en función de los contextos concretos de actuación (en este caso la cárcel o "institución total” o cerrada).

La función docente es un trabajo sujeto a determinadas condiciones materiales que definen y enmarcan las interacciones, caracterizado por un conjunto de saberes. Esta dependerá de las concepciones de animador, facilitador, formador, docente, asistente educacional, promotor social, entre otras. Sin embargo, la formación de docentes se ha centrado en modelos restrictivos de la enseńanza que han dado preeminencia a una de las tareas pedagógicas: la fase interactiva, "el dar clase", olvidándose de la práctica social y de situarse en otros escenarios, más allá de la escuela o instituto.

Al preguntarnos por el rol del docente, específicamente, en este contexto de privación de libertad, debemos indefectiblemente cuestionarnos por la formación, si en esta preparación para desarrollar la enseñanza se ha tenido en cuenta este escenario en particular. Debe- 
mos reconocer la complejidad de la tarea docente y el desarrollo de las competencias, en tanto saber hacer, de las intervenciones necesarias para atender la complejidad del rol de los educadores en cárceles y la particularidades de los educandos presos.

\section{¿CÓMO SE ENTIENDE A LA EDUCACIÓN EN CONTEXTOS DE ENCIERRO PUNITIVO?}

Las teorías criminológicas de principios del siglo XIX y en el siglo XX concebían a la educación en la cárcel como un dispositivo o tecnología de control y disciplina, junto al trabajo forzado y la religión.

En la actualidad, se la suele cruzar o someter a los fines de la pena o de la cárcel con el de la educación. Para ello, se utilizan términos como rehabilitar, resocializar, reinsertar, reeducar, entre otros "re". Es decir, la educación es pensada como una tecnología del tratamiento penitenciario de carácter terapéutico. Esto conlleva a que en la práctica y en su ejercicio diario, se la plantee como un beneficio o una mercancía de cambio por buena o mala conducta. Esto también recae en la visualización de los docentes-educadores como tecnólogos más del control y del disciplinamiento y a la escuela como un espacio diferente, en el que se tramita maquilladamente dicho control.

La concepción de que la educación debe responder a los fines de tratamiento de la pena y al discurso "re" ha llevado que los docentes se reconozcan como responsables de que esa premisa sea alcanzada. Sin encontrar diferencias entre la lógica propia del servicio y la que persigue la escuela. Eso es muy llamativo, muchos docentes que trabajan en cárceles han asumido una identidad institucional propia del servicio penitenciario.

La educación es un derecho humano que poco tiene que ver con un tratamiento terapéutico, ni la herramienta salvadora que necesita un sujeto para "re" integrarse a una sociedad que nunca le ha dado espacio ni reconocido como tal. Al reflectar la educación como derecho humano, se está pensando al sujeto de la acción educativa (la persona presa) como un sujeto de derechos. 


\section{LA INSTITUCIONALIDAD-VISIBILIDAD DEL ESCOLAR EN LA CÁRCEL}

La escuela en la cárcel funciona a modo de una institución dentro de otra, y supone conjugar prácticas educativas y marcos normativos, entre los sistemas penitenciario y educativo, cuyas lógicas de funcionamiento son totalmente diferentes, aunque en dicha conjugación hay docentes que asumen que su labor coincide con los fines del sistema penitenciario. Hay una confusión de roles, de identidad profesional, porque en el caso de algunas cárceles del norte argentino, se presentan situaciones donde la escuela, para tener funcionalidad dentro de la cárcel, debe responder a normativas que van más allá del establecido por legislaciones. Más bien responden a una cultura institucional que caracteriza al servicio penitenciario y sobre todo a esta institución totalitaria, como un currículo oculto. Por ello, pensar muchas veces en la escuela "dentro", es solo pensar en que el servicio penitenciario está "cumpliendo su deber de re-socializar a través de la educación formal”. Pero lamentablemente no nos lleva a pensarlo como un espacio ganado, lo cual responda a una sociedad más incluyente, que reconoce a todos como sujetos de derecho, puesto que la educación en establecimientos penitenciarios es uno de los escenarios más complejos y menos estudiados en Argentina. Muchas son las características diferenciales que hacen particular y condicionan la enseñanza como: las características edilicias, las formas de vincularse entre las personas, la formación, las creencias, la supervisión del proceso educativo, las normas institucionales, el traslado de los presos, entre otras.

Es importante destacar el aval de la Constitución Nacional y Provincial (en el caso de la Provincia de Salta, Argentina), mediante diferentes leyes (Ley 22.278, Ley Nacional 26.061, Ley Provincial 7.039, Ley Nacional de Educación 26.206, entre otras), de la necesidad de garantizar el acceso de calidad a la educación de personas en condiciones de privación de libertad.

No solo es necesario reconocer la institucionalidad de la escuela pública dentro de las cárceles, sino también es necesario debatir de qué manera se proporciona el espacio de intervención. Partir de esto, es necesario revisar su cultura escolar y la cultura de las prisiones. No se debe olvidar el rol de la escuela como un espacio público, de acceso irrestricto. 
La escuela no debe convertirse en una "guardería" de los/as presos/as, sino de un espacio de derecho inalienable reconocido y respetado. Justamente porque la escuela es un espacio de participación social indispensable a la hora de la formación de ciudadanía (dentro o fuera de la cárcel).

Para que haya una adecuada institucionalización de la escuela, es necesario que las cuestiones de seguridad no se presenten como obstáculos permanentes a la hora del funcionamiento de las escuelas y las organizaciones civiles. Situaciones diarias dentro de una cárcel como las sanciones y los traslados de detenidos afectan directamente el cumplimiento del derecho ${ }^{1}$.

La escuela en la cárcel debe bregar por no perder la suya esencia institucional, identidad cultural y razón de ser y estar, para que toda la tecnología del control, la vigilancia y seguridad, no invadan las aulas o el hacer del docente. Si bien se encuentra "dentro", no pertenece a la cárcel, persigue otra lógica.

El Estado no solo debe garantizar el acceso a la educación, sino también el ejercicio de una educación libre, sin condicionamientos, en que no sea "necesario" que la escuela deba negociar con el servicio penitenciario para ganar "libertades", espacios de intervención y prácticas sin un monitoreo condicionante.

\section{SOBRE LA FORMACIÓN DE EDUCADORES}

Hoy existen, en Argentina, ofertas formativas específicas para la modalidad educativa en cárceles, que fueron dadas desde el año 2009 por el Ministerio de Educación de la Nación, a través de la carrera de Pos-título "Educación en contexto de encierro", dictado por Institutos Superiores de Formación Docente y algunas universidades.

Ofertas formativas que en un primer momento, aquí en el norte argentino, solo pudieron acceder quienes se encontraban en ejercicio de la docencia en la cárcel. Pero con el tiempo se ha podido rever poco a poco, para que los estudiantes de profesorados accedieran a cursos o seminarios con la temática. Lo que sí es importante mencionar que los 
cursos u símil no se encuentran contemplados en los planes de estudios, dentro de la formación docente.

Amén de lo antedicho, es posible reconocer que los educadores son actores primordiales en el proceso educativo, por eso es fundamental revisar de manera sostenida las competencias pedagógicas, su "saber hacer”, en las escuelas en cárceles. Para ello es necesario indagar: cómo es la tarea diaria: la enseñanza más el contexto en el que se desarrolla el trabajo de los educadores; cuál es su rol dentro del proceso educativo, entendiendo que las funciones de seguridad y educación se excluyen mutuamente; cómo es la formación específica de los educadores: inicial, continua y con centralidad y presencia de la educación en derechos humanos (EDH) y el carácter de investigador de su propia práctica pedagógica.

Estos tópicos necesarios al trabajar como docentes dentro de las cárceles que deben ser presentados y ampliados dentro de la formación docente, para que al momento de ejercer su práctica enriquezca su hacer y su ser docente. Debe reconocerse que es una labor conjunta y no individualizada, es decir cooperativa.

Muchos docentes no se han preparado para enseñar dentro de las cárceles y la sensación de que se encuentran solos frente a las rejas y los ruidos ensordecedores de los candados. Contribuyen al abandono o resistencia de trabajar dentro de una escuela "intramuros".

\section{¿UNA ESCUELA ESCONDIDA?}

Al estar dentro de otra institución, se encontraría poco visible para el ministerio de educación. Recientemente, las escuelas en contexto de privación de libertad, en la provincia de Salta, se encuentran en una situación de cambio continuo de direcciones que pertenecen dentro del Sistema Educativo provincial. Por el año 2010, pertenecían a la Dirección de Regímenes Especiales marcando una concepción acerca del sujeto de enseñanza, luego hubo un cambio de paradigma, puesto que pasó a pertenecer a la dirección de Educación Secundaria, y en 2015 nuevamente se encontraban en transición hacia la Dirección de Educación de Jóvenes y Adultos. Esos cambios hablan de una nueva visión acerca de las escuelas 
que se encuentran en los penales, ya que no son personas con necesidades educativas especiales, ni tampoco adolescentes y jóvenes en su totalidad.

Esa transformación continua genera inestabilidad e incertidumbre, situación que condiciona en muchas oportunidades la continuidad de programas y proyectos educativos.

Para un acceso a la educación de calidad en contexto de privación de libertad, es importante que para el Estado, sea provincial o nacional, las escuelas de los penales dejen de estar tapadas por los muros de seguridad.

No hablamos de una educación como proceso terapéutico que ofrece el servicio penitenciario para poder cumplir con su lógica de re-inserción, sino de garantizar a todos los presos, o no, el acceso a la educación como un derecho adquirido solo por el mismo hecho de ser humano.

\section{REFERENCIAS}

DICKER, G.; TERIGI, F. La formación de maestros y profesores: hoja de ruta. Buenos Aires: Paidós, 1997.

FOUCAULT, M. Vigilar y castigar: nacimiento de la cárcel. Buenos Aires: Siglo XXI Editores, 2003.

\section{NOTAS}

1. Asumiendo un carácter normativo-regulador, las cuestiones de seguridad deben tener criterios concretos y seguir protocolos que se basen en la previsibilidad, racionalidad, proporcionalidad y legalidad (debe haber una autorización por una autoridad judicial), aunque en la mayoría de los casos, esto no se da ni se debate.

Recebido em 11 de septiembre de 2015.

Aceito em 22 de febrero de 2016. 